\title{
Identifying and prioritizing innovation criteria of projects in science and technology parks using fuzzy VIKOR
}

\author{
Javad Siahkali Moradi $^{\mathrm{a}}$, Yaser Ghorbanzad ${ }^{\mathrm{a}}$ and Mina Beig
}

${ }^{a}$ Master of Operations Research, Science and Research Branch, Islamic Azad University, Tehran, Iran

${ }^{b}$ Master of Operations Management, Najaf Abad Branch, Islamic Azad University, Isfahan, Iran

\begin{tabular}{|c|c|}
\hline A R T I C L E I N F O & ABSTRACT \\
\hline $\begin{array}{l}\text { Article history: } \\
\text { Received October 10, } 2011 \\
\text { Received in Revised form } \\
\text { November, } 14,2011 \\
\text { Accepted 26 November } 2011 \\
\text { Available online } \\
5 \text { December } 2011 \\
\text { Keywords: } \\
\text { Innovation criteria } \\
\text { Science and Technology Park } \\
\text { Fuzzy VIKOR }\end{array}$ & $\begin{array}{l}\text { The idea of Science and Technology parks has been widely used in many countries and many } \\
\text { innovative plans are initiated in these places. In this paper, we present a multiple criteria } \\
\text { decision making plan to prioritize important factors influencing the success of an innovative } \\
\text { plan. The study uses fuzzy triangular numbers to gather decision makers' feedback on different } \\
\text { criteria and rank them using fuzzy VIKOR method. The results of our survey indicate that it is } \\
\text { important to be the first who introduce the idea, the idea must be important for customers and } \\
\text { market and it must be scientifically justified. Among other important criteria, the availability of } \\
\text { experts to support the ideas and applicability in the area of human and social science are of } \\
\text { important criteria. The plan also does not need to have huge amount of investment and a } \\
\text { complicated technology and finally it should come to market in short amount of time. }\end{array}$ \\
\hline
\end{tabular}

\section{Introduction}

The recent changes of human life in terms of political, social and technological aspects have created motivation for having new ideas based creativity and innovation (Zahabioun, 2009). Creativity and innovation not only leads business partners to provide more competitive products, but also it helps them reduce the cost of production, which increases productivity and efficiency (Ngah \& Ibrahim, 2009). One immediate expectation for innovative organization is to make the necessary change in their organizational infrastructure (Siegel, 2003). Innovation is one of the most important growth elements especially in developing countries. Science and Technology Park, as one of the most significant centers of receiving and processing ideas and innovative projects, plays an important role in making the innovation pervasive. Empowering the Science and Technology Park and improvement of innovative ideas acceptance preconditions, can empower the countries in innovation and technology (Westhead, 2000).

* Corresponding author. Tel.: +989122520885

E-mail addresses: syahkaly@yahoo.com (J. Siahkali Moradi) 
Science and Technology Park acts as a catalyst and accelerates the process of responding to different needs of industries. Supporting innovative plans is one of the most important activities of these centers (Hasson, 2005). One important factor in developing innovative products is the limitation in budgets, which leads us to prioritize different ideas for cost allocation. Any ranking of possible alternatives must be accomplished through precise and comprehensive criteria. This is normally a challenging task since different people consider various criteria and a good ranking of alternative is a tedious task.

In this paper, we present an empirical study to rank important criteria influencing the success of Science and Technology Parks. Next, we briefly discuss the idea of the parks and innovations and then present the implementation of Fuzzy VIKOR for ranking different alternatives.

\section{Science and technology park}

The idea of science parks was first introduced during the years of 1950s when policy makers in United States were planning to establish some industrial sites near scientific centers just like universities and the first unit was established near the Stanford University (Hansson, 2004-5). Since then, scientific parks have become important components of growing economies and European and Asian countries have followed the idea of scientific parks (Massey et al., 1992; Clark, 2003). There different definitions for scientific parts but there are some common issues among all of them, which are as follows,

- A real estate development;

- An organizational program of activities for technology transfer;

- A partnership between academic institutions, government and the private sector (AURRP, 1998).

The European Commission has another definition of Science Park, called as "a business incubator", representing a place where newly created firms are concentrated in a limited space. The primary aim of incubators is to improve the chance of growth and rate of survival of these firms by providing them with a modular building with common facilities (European Union 1990, Hansson, 2004).

There are a number of benefits from establishment of science and technology parks, where some researchers focused their studies on. For example, Guy (1996) believes that one of the important benefits of establishing the science park is to prepare a wide and confident infrastructure of technical and administrative support that is essential for a new young firm in business world. In a particular country, where huge number of firms consists of small to medium firms, the importance of this support will rise (Cooper, 1985). Lin and Tzeng (2009) stated that science parks play important role in continuous growth and development in value created systems. Hansson (2004) investigated the structure of science and technology parks as knowledge based organizations. In addition, Link and Scott (2004) studied the impact of science and technology parks in innovation and relieving some obstacles in the way of manufacturer.

\section{Innovation and Creativity}

Innovation can be defined as the ability to make positive changes in products, services, processes, and currents methods. Gilford (1950) is believed as one of the first who discussed the importance of creativity and innovation and stated creativity as "divergent thinking". Luthans, et al. (2004) defined creativity as creating a combination of people's thoughts and solutions for a new method. Afuah (1998) defined creativity as the cognitive process of creation of an idea, concept, or a novel discovery. Lundvall (1992) defined creativity as a phenomenon, which occurs when someone organizes his or her thinking to better understand a subject or situation. Ngah and Ibrahim (2009) studied the relationship of intellectual capital, innovation and organizational performance for 
Malaysian SMEs. Mian (1997) presented an empirical study for assessing and managing the university technology business incubator using an integrated framework. Mian (1996), in other assignment, evaluated value-added contributions of university technology business incubators for some tenant firms.

Innovation means to use a new science to provide a new product or service, which is demanded by customers. This innovation is a combination of creativity and commercialization. According to Porter (1985), innovation is the new way of making commercialized product. The innovation process cannot be separate from the strategic and competitive context. We have to consider that for an idea to be innovative it must be generalized to the customers' demanded products or services (Damanpour, et al., 1989). Innovation is a managerial system, which emphasizes on organization's mission, looks for exceptional opportunities, determines whether or not it is suitable for the organization's strategic direction, and determines the success criterions. Porter (1985) explained that companies must be able to create a flow of products and processes to use more technologies and meanwhile move towards their company's stability. There are other findings on innovation, which emphasizes on product innovation of producing companies. From organizational perspective, the real success of any innovation happens in the market (Maravelakis, et al., 2006).

The change of the laws and regulations regarding strategic innovation has been the key factor of many market managers. In addition, companies must try to create the proper culture, structure, motivators, systems and processes that can facilitate innovation (Damanpour, 1991). In organization, innovation can be like changes or small improvements in trends of works or services and sometimes it is in infrastructure. The meaning of innovation can be a positive change in modern processes, new structures, new administrative systems, and new programs. Innovation like creativity, have the elements of freshness, newness, novelty, and being introduced for the first time (Damanpour, 1991). In summary, innovation is actualized creativity, that is, new ideas becoming reality. From this viewpoint, innovation can be defined as realization of mental creativity.

\section{Fuzzy VIKOR method}

MCDM models are the most popular approaches, which help managers and decision makers make their decisions in a better and confident way in the conflicting circumstances (Duckstein \& Opricovic, 1980; Pakdin Amiri et al., 2011).

There are some steps for devising an MCDM model as are stated below:

a) Establishing a system for criteria evaluation that can relate system capabilities to goals;

b) Developing alternative systems for attaining the goals;

c) Evaluating alternatives in terms of criteria;

d) Applying a normative multi criteria analysis method;

e) Accepting one alternative as optimal (preferred);

f) If the final solution is not acceptable, we should gather new information and go back into the first iteration of multi criteria optimization(Opricovic and Tzeng 2004; Amiri et al., 2011).

For proposing an MCDM model in the real-world applications, we are facing with a lot of uncertain and vague situations. For solving this problem, Zadeh (1965) proposed fuzzy sets, which is a qualified instrument to deal with vagueness and fuzziness of human judgments (Yang et al., 2008; Amiri, 2011).

The VIKOR method is an appropriate MCDM model and was developed for solving multiple criteria optimization in the complex systems. This method focuses on ranking and selecting the best combination of different alternatives (Opricovic \& Tzeng, 2004; Opricovic, 2008). VIKOR method has been proposed to solve a problem with non-commensurable and conflicting criteria (Opricovic \& Tzeng, 2004; Opricovic, 2008; Sayadi et al., 2009; Amiri et al., 2011). 
VIKOR method algorithm is like TOPSIS method, which is based on an aggregating function that represents "closeness of alternatives to ideal point" (Opricovic \& Tzeng 2004). It means that VIKOR method is similar TOPSIS method, for determining the ranking list. The main difference with TOPSIS is that this method uses vector normalization but VIKOR method uses linear normalization (Tzeng et al., 2005). In addition, TOPSIS method selects an alternative, which is in the shortest distance from the positive ideal solution (PIS) and the farthest from the negative ideal solution (NIS) as the best ranked alternative (Chu et al., 2007) but in VIKOR method, it calculates ratio of positive and negative ideal solution, and then provides the best preferred rank. Thus, VIKOR is proposing a compromise solution with an advantage rate (Tzeng et al., 2005; Amiri et al., 2011).

Application of VIKOR method under fuzzy circumstance is forcing us to combine this method with fuzzy sets theory. Fuzzy VIKOR would discover the best solution and a compromise solution, which could be implemented to solve a fuzzy MCDM problem. Fuzzy VIKOR can help managers and decision makers determine the preferred solutions for a decision problem in the real-world organizational situations. There are some steps in forming the procedure of fuzzy VIKOR that are stated as below (Chen \& Wang 2009; Amiri et al., 2011):

Step 1: Form the feasible alternatives, specify the evaluation criteria, and determine the group of decision makers by assuming that there are $m$ alternative, $k$ evaluation criterion, and $n$ decision maker,

Step 2: Define the linguistic variables and their corresponding triangular fuzzy numbers (TFN),

Linguistic variables are used to assess the importance of the criteria and to rate alternatives with respect to various criteria. A TFN can be defined as a triplet $\tilde{A}=\left(a_{1}, a_{2}, a_{3}\right)$ of crisp numbers with $a_{1}<a_{2}<a_{3}$ and membership function $f_{\tilde{A}}(x)$ of the fuzzy number $\tilde{A}$ is as follows, (Binwahlan, 2009; Amiri et al., 2011).

$$
f_{\tilde{A}}(x)=\left\{\begin{array}{cc}
0 & x<a_{1}, x>a_{3} \\
\frac{\left(x-a_{1}\right)}{\left(a_{2}-a_{1}\right)} & a_{1} \leq x \leq a_{2} \\
\frac{\left(x-a_{3}\right)}{\left(a_{2}-a_{3}\right)} & a_{2} \leq x \leq a_{3}
\end{array}\right.
$$

let $\mathrm{a}_{1}$ and $\mathrm{a}_{2}$ be two triangular fuzzy numbers (TFN) parameterized by the triplet $\left(a_{1}, a_{2}, a_{3}\right)$ and $\left(b_{1}, b_{2}, b_{3}\right)$, respectively. The following arithmetic operations hold for the proposed model of this paper.

$\tilde{A} \oplus \tilde{B}=\left(a_{1}, a_{2}, a_{3}\right) \oplus\left(b_{1}, b_{2}, b_{3}\right)=\left(a_{1}+b_{1}, a_{2}+b_{2}, a_{3}+b_{3}\right)$

$\tilde{A}(-) \tilde{B}=\left(a_{1}, a_{2}, a_{3}\right)(-)\left(b_{1}, b_{2}, b_{3}\right)=\left(a_{1}-b_{3}, a_{2}-b_{2}, a_{3}-b_{1}\right)$

$\tilde{A} \otimes \tilde{B}=\left(a_{1}, a_{2}, a_{3}\right) \otimes\left(b_{1}, b_{2}, b_{3}\right)=\left(a_{1} b_{1}, a_{2} b_{2}, a_{3} b_{3}\right)$

$\tilde{A}(\div) \tilde{B}=\left(a_{1}, a_{2}, a_{3}\right)(\div)\left(b_{1}, b_{2}, b_{3}\right)=\left(a_{1} / b_{3}, a_{2} / b_{2}, a_{3} / b_{1}\right)$

$k \tilde{A}=\left(k a_{1}, k a_{2}, k a_{3}\right)$

$(\tilde{A})^{-1}=\left(\frac{1}{a_{3}}, \frac{1}{a_{2}}, \frac{1}{a_{1}}\right)$

Based on Chou and Chang (2008) studies, a seven-scale linguistic variable fuzzy number is used to access the importance of evaluation criteria with a fuzzy set. The linguistic scales and corresponding TFNs for the weight of criteria and the rating of alternatives are shown in Table 1 and Table 2. 


\section{Table 1}

Linguistic terms for the importance weights

\begin{tabular}{ccccccc}
\hline Very low $(\mathrm{VL})$ & Low $(\mathrm{L})$ & Medium low $(\mathrm{ML})$ & Medium $(\mathrm{M})$ & Medium high $(\mathrm{MH})$ & High $(\mathrm{H})$ & Very high $(\mathrm{VH})$ \\
\hline$(0,0,0.1)$ & $(0,0.1,3)$ & $(0.1,0.3,0,5)$ & $(0.3,0.5,0.7)$ & $(0.5,0.7,0.9)$ & $(0.7,0.9,1)$ & $(0.9,1,1)$ \\
\hline
\end{tabular}

\section{Table 2}

Linguistic terms for the fuzzy rating

\begin{tabular}{lllllll}
\hline Very bad (VB) & Bad (B) & Medium bad (MB) & Medium (M) & Medium good (MG) & Good (G) & Very Good (G) \\
\hline$(0,0,1)$ & $(0,1,3)$ & $(1,3,5)$ & $(3,5,7)$ & $(5,7,9)$ & $(7,9,10)$ & $(9,10,10)$
\end{tabular}

Step 3: Integrate decision makers' preferences and opinions. Aggregating the fuzzy weight of criteria and fuzzy rating of alternatives from $\mathrm{n}$ decision-maker calculated derives the decision:

$$
\tilde{w}_{j}=\frac{1}{n}\left[\sum_{e=1}^{n} \tilde{w}_{j}^{e}\right], j=1,2, \ldots, k
$$

In addition, the preferences and opinions of $\mathrm{n}$ decision-maker with respect to $\mathrm{j}$ criterion for the important weight of each criterion and the rating of each alternative in the ith alternative can be calculated by:

$$
\tilde{X}_{i j}=\frac{1}{n}\left[\sum_{e=1}^{n} \tilde{X}_{i j}^{e}\right], i=1,2, \ldots, m
$$

Step 4: Evaluate fuzzy weighted mean and build the (normalized) fuzzy decision matrix:

$$
\begin{aligned}
& \begin{array}{llll}
C_{1} & C_{2} & \cdots & C_{k}
\end{array}
\end{aligned}
$$

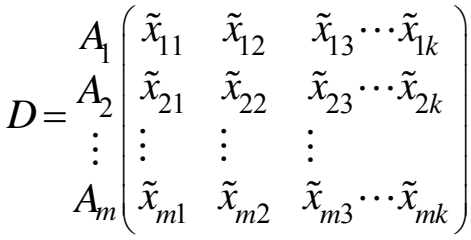

$$
\begin{aligned}
& \tilde{W}=\left[\tilde{w}_{1}, \tilde{w}_{2}, \ldots, \tilde{w}_{k}\right]
\end{aligned}
$$

where $x$ is the rating of each alternative with respect to each criterion, and $w$ is the importance weight of the $j^{\text {th }}$ criterion.

Step 5: Calculate fuzzy best value (FBV) and fuzzy worst value (FWV):

$$
\tilde{f}_{j}^{*}=\max _{i} \tilde{x}_{i j}, \tilde{f}_{j}^{-}=\min _{i} \tilde{x}_{i j}, i=1,2, \ldots, m ; j=1,2, \ldots, k
$$

Step 6: Evaluate the following values,

$$
\begin{aligned}
& \frac{\tilde{w}_{j}\left(\tilde{f}_{j}^{*}-\tilde{x}_{i j}\right)}{\left(\tilde{f}_{j}^{*}-\tilde{f}_{j}^{-}\right)}, \\
& \tilde{S}_{i}=\sum_{i=1}^{k} \frac{\tilde{w}_{j}\left(\tilde{f}_{j}^{*}-\tilde{x}_{i j}\right)}{\left(\tilde{f}_{j}^{*}-\tilde{f}_{j}^{-}\right)},
\end{aligned}
$$


$\tilde{R}_{i}=\max _{j}\left[\frac{\tilde{w}_{j}\left(\tilde{f}_{j}^{*}-\tilde{x}_{i j}\right)}{\left(\tilde{f}_{j}^{*}-\tilde{f}_{j}^{-}\right)}\right]$,

where $\tilde{S}_{i}$ and $\tilde{R}_{i}$ represent the utility measure and the regret measure, respectively, and $\tilde{w}_{j}$ is the weight of the $j^{\text {th }}$ criterion (Tong et al 2005). We calculate $\tilde{S}_{i}$ and $\tilde{R}_{i}$ with respect to all criteria, which are calculated by the sum of the distance for the FBV

Step 7: Calculate the following values,

$\tilde{S}^{*}=\min _{i} \tilde{S}_{i}, \tilde{S}^{-}=\max _{i} \tilde{S}_{i}$,

$\tilde{R}^{*}=\min _{i} \tilde{R}_{i}, \tilde{R}^{-}=\max _{i} \tilde{R}_{i}$,

$\tilde{Q}_{i}=v \frac{\left(\tilde{S}_{j}-\tilde{S}^{*}\right)}{\left(\tilde{S}^{-}-\tilde{S}^{*}\right)}+(1-v) \frac{\left(\tilde{R}_{j}-\tilde{R}^{*}\right)}{\left(\tilde{R}^{-}-\tilde{R}^{*}\right)}$,

where, $\tilde{S}^{*}$ is the minimum value of $\tilde{S}_{i}$, which is the maximum majority rule or maximum group utility, and $\tilde{R}^{*}$ is the minimum value of $\tilde{R}_{i}$, which is the minimum individual regret of the opponent. Therefore, the index of $\tilde{Q}_{i}$ is calculated based on the both the group utility and individual regret of the opponent. In addition, $v$ represents the weight of the strategy for the maximum group utility (Wu et al., 2007). When $v>0.5$, the decision goes towards the maximum majority rule; and when $v \leq 0.5$, the decision tends toward the individual regret of the opponent. Hence, $v$ is introduced as weight of the strategy of 'the majority of attributes'. Normally, the value of $v$ is taken as 0.5 . However, $v$ can take any value from 0 to 1(Bazzazi, et al., 2011). Rank and improve the alternatives, sort by the values $\mathrm{S}, \mathrm{R}$, and $\mathrm{Q}$, in non-increasing order and reduce the gaps in the criteria. The results are three ranking lists, with the best alternatives having the lowest value (Wu et al., 2007; Amiri et al., 2011).

\subsection{Research model}

In this section, we present details of our proposed model for ranking innovative ideas for science parks. The proposed model of this paper uses experts' opinion and gathers all important criteria to use Fuzzy VIKOR for ranking the innovative ideas and details are shown in Fig. 1.

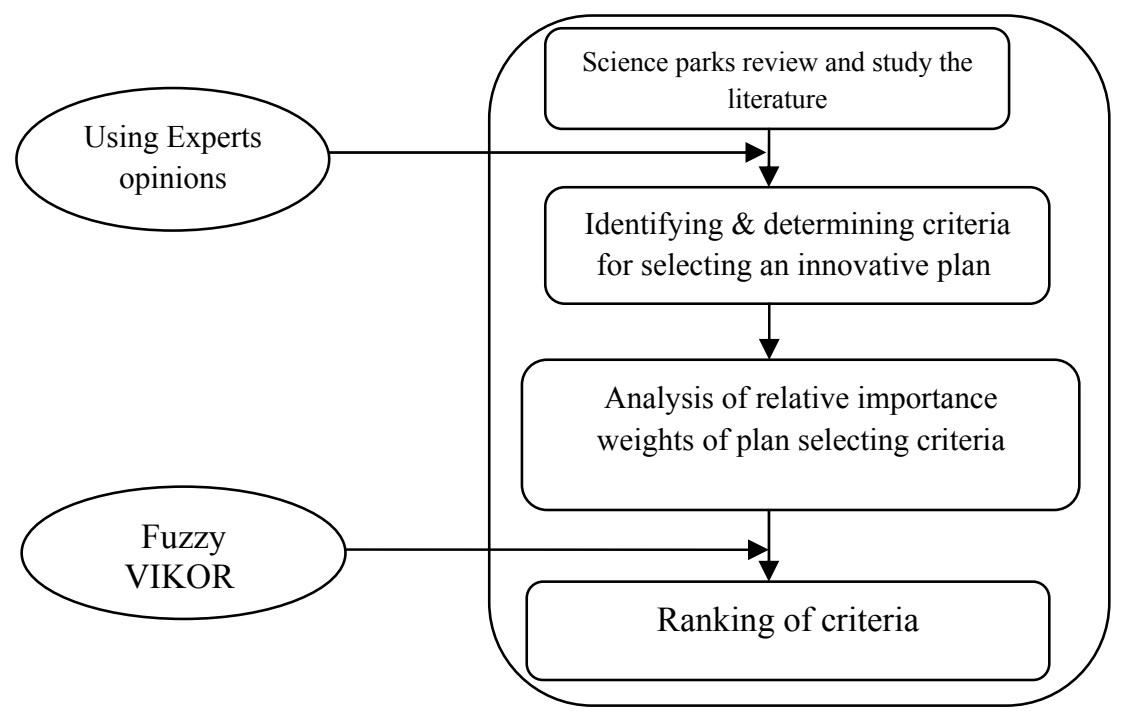

Fig. 1. Criteria identification and prioritization framework of the research 


\subsection{Innovation Criteria}

Innovation criteria, which are based on the research of focused groups, include:

1. Being Initiative in the market, 8. Legality,

2. Originality (having no internal of foreign 9. Being valuable for customers and market, counterpart),

3. Scientific justifiability,

4. Novel technology,

5. Does not need a complex technology,

6. Does not need huge investing,

7. Available experts in the field,

10. High profitability,

11. Short period of time accomplishment,

12. Low risk,

13. High capacity of usage after implementation,

14. Meet a special need of market,

15. Be in the area of human and social science.

Among the 15 criteria, 8 criteria were selected based on the suggestions of experts. These 8 criteria and their interactions model on innovative ideas are as follow,

1. Being initiative in the market $\left(\mathrm{A}_{1}\right)$,

2. Scientific justifiability $\left(\mathrm{A}_{2}\right)$,

3. Does not need a complex technology $\left(\mathrm{A}_{3}\right)$,

4. Being valuable for customers and market $\left(\mathrm{A}_{4}\right)$,
5. Be in the area of human and social science $\left(\mathrm{A}_{5}\right)$,

6. Does not need huge investing $\left(\mathrm{A}_{6}\right)$,

7. Available experts in the field $\left(\mathrm{A}_{7}\right)$,

8. Short period of time accomplishment $\left(\mathrm{A}_{8}\right)$,

Next, we need to determine the relative importance of each particular criterion. The weights are calculated based on gathering the feedbacks received from five experts who are influential on decision making about plans selection in Iranian science parks. Table 3 shows details of our survey in terms of triangular fuzzy numbers.

\section{Table 3}

Decision matrix and weight importance of the criteria

\begin{tabular}{lcccccc}
\hline & \multicolumn{7}{c}{ Decision makers } \\
Criteria & $D M_{1}$ & $D M_{2}$ & $D M_{3}$ & $D M_{4}$ & $D M_{5}$ & Weights \\
\hline $\mathrm{A}_{1}$ & $(5,7,8.5)$ & $(3.8,5.2,7.8)$ & $(6.6,8.6,9.6)$ & $(4.2,6.2,8)$ & $(3.6,4.8,7.2)$ & $(.024, .03, .06)$ \\
$\mathrm{A}_{2}$ & $(3.8,5.8,7.6)$ & $(3.3,5.16,6.8)$ & $(4.3,6.3,8.16)$ & $(4,6,8.16)$ & $(3.66,5,6.5)$ & $(.44, .69,1)$ \\
$\mathrm{A}_{3}$ & $(3.4,4.4,7.2)$ & $(5.66,7.5,8.3)$ & $(5.4,7.4,9)$ & $(5.4,7.4,9)$ & $(3.8,4.8,7.6)$ & $(.17, .3, .47)$ \\
$\mathrm{A}_{4}$ & $(3.6,5.2,6.6)$ & $(4.4,6,7.6)$ & $(5.4,7.4,9)$ & $(4.2,6.2,8)$ & $(4.6,6.4,7.8)$ & $(.03, .05, .08)$ \\
$\mathrm{A}_{5}$ & $(4.6,6.4,8)$ & $(4.6,6.4,7.8)$ & $(3,3.6,5.4)$ & $(3.8,5.4,7.4)$ & $(4,5.6,7)$ & $(.02, .03, .063)$ \\
$\mathrm{A}_{6}$ & $(4,6,7.8)$ & $(5.33,7.1,8.5)$ & $(6,7.6,9)$ & $(7,8.66,9.5)$ & $(4,5.5,7)$ & $(.21, .36, .59)$ \\
$\mathrm{A}_{7}$ & $(5.8,7.4,8.4)$ & $(6.6,8.4,9.4)$ & $(5.2,7.14,8.7)$ & $(4.83,6.5,8)$ & $(1.8,3.8,5.8)$ & $(.095, .17, .3)$ \\
$\mathrm{A}_{8}$ & $(2.4,4.2,6.2)$ & $(2.4,5.1,7.3)$ & $(5.4,7.2,8.8)$ & $(5,7.4,8.4)$ & $(4.6,6.4,8)$ & $(.01, .017, .02)$ \\
\hline
\end{tabular}

Using the proposed method of the paper yields the following ranking for eight alternatives,

\begin{tabular}{lcccccccc}
\hline Alternative & $A_{1}$ & $A_{4}$ & $A_{2}$ & $A_{7}$ & $A_{5}$ & $A_{6}$ & $A_{3}$ & $A_{8}$ \\
\hline$Q_{i}$ & $(.09, .22, .5)$ & $(.10, .31, .85)$ & $(.101, .42, .81)$ & $(.103, .8, .79)$ & $(.104, .5,1)$ & $(.106, .59, .74)$ & $(.109, .8,79)$ & $(.11, .64, .83)$ \\
Rank & 1 & 2 & 3 & 4 & 5 & 6 & 7 & 8 \\
\hline
\end{tabular}

As we can observe, the first criterion gains the highest ranking, which means it is important to be the first who introduce the idea. The next important criterion is to be important for customers and market, the third important criteria explains that a plan must be scientifically justified. The next important criterion is the availability of experts to support the ideas. Our decision makers suggest that idea is preferably in the area of human and social science, it does not need to have huge amount of 
investment and a complicated technology and finally it should come to market in short amount of time.

In summary, science and technology parks play an important role for the growth of economy since it relies on creativity and innovation. Unfortunately, there are several limitations on developing the idea of science and technology parks such as regulatory, sufficient accommodation, etc. These days, we are witness of sluggish economy around world, where business partners are downsizing or closing their units. In such economy, there is a strong need to support products with innovative ideas and Science and Technology parks could fill the gap in this economy.

\section{Conclusion}

In this paper, we have presented an empirical study using a multiple criteria decision making technique to prioritize important factors influencing the success of an innovative plan. The study implemented fuzzy triangular numbers to gather decision makers' feedback on different criteria and rank them using fuzzy VIKOR method. The results of our survey indicated that it is important to be the first who introduce the idea, the idea must be important for customers and market and it must be scientifically justified. Among other important criteria, the availability of experts to support the ideas and applicability in the area of human and social science are of important criteria. The plan also does not need to have huge amount of investment and a complicated technology and finally it should come to market in short amount of time.

\section{Acknowledgment}

This paper was financially assisted by Islamic Azad University and the authors would like to thank the people who supported the work. The authors also would like to thank the anonymous referees for their constructive comments on earlier version of this work.

\section{Reference}

Afuah, A. (1998). Innovation Management. Oxford Press, UK.

Amiri, M., Ayazi, S.A., LayaOlfat, \& Siahkali Moradi, J. (2011). Group Decision Making Process for Supplier Selection withVIKOR under Fuzzy Circumstance; Case Study: An Iranian Car Parts Supplier. International Bulletin of Business Administration, 10, 62-75.

Amiri, M., Hadadi, B., Amirkhani, A.H., \& Izadbakhsh, H. (2008). Supplier selection via principles component analysis: An empirical examination. Journal of Applied Science, 8 (20), 3715-3720.

AURRP: Association of University Related Research Parks (AURRP). (1998). Instruction and related discussion about science and research parks; Website: http://aurrp.org/more/calendar.php

Bazzazi, A.A., Osanloo, M., \& Karimi, B. (2011). Deriving preference order of open pit mines equipment through MADM method: Application of modified VIKOR method. Expert Systems with Applications, 38, 2550-2556.

Binwahlan, M.S., Salim, N., \& Suanmali, L. (2009). Intelligent model for automatic text summarization. Information Technology Journal, 8 (8), 1249-1255.

Chen, L.Y., \& Wang, T.C. (2009). Optimizing partners' choice in IS/IT outsourcing projects: The strategic decision of fuzzy VIKOR. International Journal of Production Economics, 120, 233-242.

Chen, R.C., Chen, T.T., \& Fang, W.L. (2009). Assignment of external off the job training courses to employees using genetic algorithm. Information Technology Journal, 8(2), 147-155.

Chou, S.Y., \& Chang, Y.H. (2008). A decision support system for supplier selection based on a strategy-aligned fuzzy SMART approach. Expert Systems with Applications, 34(4), 2241-2253.

Chu, M.T., Shyu, J., Tzeng, G.H., \& Khosla, R. (2007). Comparison among three analytic methods for knowledge communication group decision analysis. Expert Systems with Applications, 33, $1011-1024$. 
Clark, W.W. Jr. (2003). Science parks: Theory and background. International Journal of Technology Transfer Commercialize, 2, 150-178.

Cooper, A.C. (1985). The role of incubator organizations in the founding of growth-oriented firms. Journal of Business Venturing, 1, 75-86.

Damanpour, F. (1991). Organizational innovation: A meta-analysis of effects of determinants and moderators. Academic Management Journal, 34(3), 555-590.

Damanpour, F., Szabat, K.A., \& Evan, M. (1989). The relationship between types of innovation and organizational performance. Journal of Management Studies, 26(6), 587-602.

Duckstein, L., \& Opricovic, S. (1980). Multi objective optimization in river basin development. Water Resources, 16(1):14-20.

Guy, I. (1996). A look at Aston Science Park. Technovation, 16, 217-218.

Hansson, F. (2004). Science parks as knowledge organization -The 'ba' in action? MPP Working, ISBN: 87-91181-86-0.

Hansson, F., Husted, K., \& Vestergaard, J. (2005). Second generation science parks: From structural holes jockeys to social capital catalysts of knowledge society. Technovation, 25, 1039-1049.

Lin, C. L., \& Tzeng, G. (2009). A value-created system of science (technology) park by using DEMATEL. Expert Systems with Applications, 36, 9683-9697.

Link, A. N., \& Scott, J. T. (2004). U. S. Science Parks: The Diffusion of an Innovation and Its Effects on the Academic Missions of Universities. JEL Classifications: I2, L31, O32, R1, 1-43.

Lundvall, B.A. (1992). National System of Innovation: Towards a Theory of Innovation and Interactive Learning. Pinter Pub Ltd., London.

Luthans, F., Luhans, K.W. \& Luthans, B.C. (2004). Positive psychological capital: Human and social capital. Business Horizons, 41(10), 45-50.

Maravelakis E., Bilalisz, N., Antoniadisy, A., \& Jones, K.A., \& Moustakis, V. (2006). Measuring and benchmarking the innovativeness of SMEs: A three-dimensional fuzzy logic approach. Production Planning \& Control, 17(3), 283-929.

Massey, D., Quintas, P., \& Wield, D. (1992). High Tech Fantasies: Science Parks in Society, Science and Space. Rout Ledge, Londan, UK., ISBN-10: 0415013380, Pp: 288

Mian, S.A. (1996). Assessing value-added contributions of university technology business incubators to tenant firms. Resources Policy, 25(3), 325-335.

Mian, S.A. (1997). Assessing and managing the university technology business incubator: An integrative framework. Journal of Business Venture, 12, 251-285.

Ngah, R., \& Ibrahim, A.R. (2009). The Relationship of Intellectual Capital, Innovation and Organizational Performance: a Preliminary Study in Malaysian SMEs. International Journal of Management Innovation Systems, 1(1), 1-13.

Opricovic, S., \& Tzeng, G.H. (2004). Compromise solution by MCDM methods: A comparative analysis of VIKOR and TOPSIS. European Journal of Operational Research, 156, 445-455.

Opricovic, S., \& Tzeng, G.H. (2007). Extended VIKOR method in comparison with outranking methods. European Journal of Operational Research, 178, 514-529.

Opricovic, S. (2008). A compromise solution in water resources planning. Water Resource Management, 23, 1549-1561.

Pakdin Amiri, A., Pakdin Amiri, M., Pakdin Amiri, M. (2009). The investigation and Explanation of local model of effective internal factors on stock price index in Tehran stock exchange with fuzzy approach. Journal of Applied Sciences, 9 (2), 258-267.

Porter, M. (1985). Advantage, Creating and Sustaining Superior Performance, Simons, ISBN: 0-68484146-0.

Sayadi, M.K., Heydari, M., \& Shahanaghi, K. (2009). Extension of VIKOR method for decision making problem with interval numbers. Applied Mathematical Modeling, 33, 2257-2262.

Siegel, D., West head, P., \& Wright, M. (2003a). Science parks and the performance of new technology-based firms: A review of recent UK evidence and an agenda for future research. Small Business Economics, 20, 177-184. 
Siegel, D.S., West head, P., Wright, M. (2003b). Assessing the impact of university science parks on research productivity: Exploratory firm-level evidence from the United Kingdom. International Journal of Industrial Organization, 21, 1357-1369.

Tong, L.I., Chen, C.C., \& Wang, C.H. (2005). Optimization of multi response process using the VIKOR method. International Journal of Advanced Manufacturing Technology, 31, 1049-1057.

Tzeng, G.H., Lin, C.W., \& Opricovic, S. (2005). Multi criteria analysis alternative fuel buses for public transportation. Energy Policy, 33,1373-1383.

West Head, P., Batstone, S., \& Martin, F. (2000).Technology-based firms located on Science Parks: The applicability of bullock's soft-hard model. Enterprise Innovate. Management Studies, 1, 107139.

Wu, C.R., Lina, C.T., \& Chen, H.C. (2007). Optimal selection of location for Taiwanese hospitals to ensure a competitive advantage by using the analytic hierarchy process and sensitivity analysis. Building Environment, 42(3), 1431-1444.

Yang, J.L., Chiu, H.N., Tzeng, G.H., \&Yeh, R.H. (2008). Vendor selection by integrated fuzzy MCDM techniques with independent and interdependent relationships. Information Science, 178, 4166-4183.

Zahabioun, S. (2009). Identification of CSF for establishing and developing ICT parks in Iran. Master's Thesis, Lulea University of Technology, ISSN: 1653-0187. 